\title{
INHIBITION OF THE DNA AMPLIFICATION OF TRYPANOSOMES PRESENT IN TSETSE FLIES MIDGUTS: IMPLICATIONS FOR THE IDENTIFICATION OF TRYPANOSOME SPECIES IN WILD TSETSE FLIES
}

\author{
RAVEL S.*, MARIANI C.*, GRÉBAUT P.*, JAMONNEAU V.*, CUISANCE D.* \& CUNY G.*
}

\begin{abstract}
Summary:
The present study was carried out in order to investigate if there was really a failure of PCR in identifying parasitologically positive tsetse flies in the field. Tsetse flies /Glossina palpalis gambiensis and Glossina morsitans morsitans) were therefore experimentally infected with two different species of Trypanosoma (Trypanosoma brucei gambiense or Trypanosoma congolense). A total of 152 tsetse flies were dissected, and organs of each fly (midgut, proboscis or salivary glands) were examined. The positive organs were then analysed using PCR. Results showed that, regardless of the trypanosome species, PCR failed to amplify $40 \%$ of the parasitologically positive midguts. This failure, which does not occur with diluted samples, is likely to be caused by an inhibition of the amplification reaction. This finding has important implications for the detection and the identification of trypanosome species in wild tsetse flies.
\end{abstract}

KEY WORDS : Glossina palpalis gambiensis, Glossina morsitans morsitans, Trypanosoma brucei gambiense, Trypanosoma congolense, PCR inhibition.

T The various trypanosome species infecting tsetse flies must be accurately identified if a better understanding of the epidemiology of the disease is to be achieved. Due to its higher sensitivity, polymerase chain reaction (PCR) tends to complete or replace the traditional dissection and examination technique used to detect and identify trypanosome infections in wild tsetse flies (McNamara et al., 1995; Solano et al., 1995, 1996). Moreover, its high specificity, makes it possible to identify the trypanosomes below subgenus level and, importantly, to reveal mixed infections (Masiga et al., 1996; Morlais et al., 1998a).

\footnotetext{
* Laboratoire de Recherche et de Coordination sur les Trypanosomoses, UR035 IRD-CIRAD, Programme Santé Animale, TA 207/G, Campus International de Baillarguet, 34398 Montpellier Cedex 5, France.

Correspondence: Dr. S. Ravel

Tel./fax: 33 (0)4 67593920 - E-mail: ravel@mpl.ird.fr
}

Résumé : INHIBITION DE L'AMPLIFICATION DE L'ADN DE TRYPANOSOMFS PRÉSENTS DANS LE TUBE DIGESTIF DE MOUCHES TSÉTSÉ : IMPLICATION POUR L'IDENTIFICATION DES ESPÈCES DE TRYPANOSOMES CHEZ LES GLOSSINES SUR LE TERRAIN

La présente étude a été conduite dans le but de vérifier si l'échec de la PCR pour identifier les mouches tsétsé porteuses de trypanosomes sur le terrain était du à une inhibition de la réaction d'amplification ou bien à l'absence d'amorces spécifiques de certaines souches de trypanosomes. Pour ce faire, des infections expérimentales de glossines (Glossina palpalis gambiensis et Glossina morsitans morsitans) avec deux espèces différentes de trypanosomes (Trypanosoma brucei gambiense ou Trypanosoma congolense) ont été réalisées. 152 glossines ont été disséquées et les organes de chaque mouche lintestin, proboscis ou glandes salivaires) ont été examinés. Les organes positifs ont ensuite été analysés par PCR. Les résultats montrent que, quelle que soit l'espèce de trypanosomes, $40 \%$ des intestins positifs à l'observation ne sont pas amplifiés par la PCR. Ce problème, résolu en diluant les échantillons, est probablement dû à l'inhibition de la réaction d'amplification. Ceci a d'importantes implications pour la détection et l'identification des espèces de trypanosomes chez les glossines sur le terrain.

MOTS CLÉS : Glossina palpalis gambiensisis, Glossina morsitans morsitans, Trypanosoma brucei gambiense, Trypanosoma congolense, inhibition de la PCR

However, PCR sometimes failed to identify parasitologically positive flies (Woolhouse et al., 1996; Morlais et al., 1998b). The question remains whether this could be due to inhibitors of the amplification reactions or to the absence of certain primers specific of existing trypanosome subgroups (McNamara et al., 1994; Solano et al., 1995). Another reason might be that divergence between trypanosome sequences could exist according to geographical location, thus preventing species-specific primers from recognizing all the trypanosomes of a same species (Morlais et al., 1998b).

Previous observations (data not shown) led us to suspect PCR inhibition could exist. To test this hypothesis, experimental infections of tsetse flies were conducted with two Trypanosoma, Trypanosoma brucei gambiense or Trypanosoma congolense savannah type, for which specific primers are available. Tsetse organs were first observed by microscopy, then positive organs were subjected to PCR using the corresponding specific set of primers. 


\section{MATERIALS AND METHODS}

\section{TSETSE AND TRYPANOSOMES}

T the Glossina palpalis gambiensis and Glossina morsitans morsitans used here are bred in colonies kept at CIRAD-EMVT in Montpellier, France, and originally come from, respectively, Burkina Faso and Zimbabwe. T. congolense clone E325 (savannah type) was isolated from infected wild Glossina pallidipes caught in Uganda (Uilenberg et al., 1973), whereas T. b. gambiense A005 was isolated in 1989 from humans, in Fontem, Cameroon (Dukes et al., 1989).

\section{INFECTION OF TSETSE FLIES}

G. p. gambiensis were infected with procyclic culture forms of T. $b$. gambiense using the membrane feeding technique. Flies failing to feed were removed from the experiment and the remaining blood-filled flies were subsequently left to feed on an uninfected rabbit until the end of the experiment. G. p. gambiensis and G. $m$. morsitans were infected with $T$. congolense clone E325 by letting teneral flies feed on the belly of infected mice (when parasitaemia was between $3 \times 10^{7}$ and $10^{8}$ trypanosomes $/ \mathrm{ml}$ ). Again, flies failing to feed were removed and the remaining blood-filled flies were subsequently maintained on two uninfected rabbits, one for each fly species, until the end of the experiment. Infection was assessed by dissecting each fly after four days starvation (five or six days for the most part) and 48 days post-infection, with examination of the midgut and salivary glands (when infected with T. b. gambiense) or midgut and proboscis (in the case of $T$. congolense) by phase-contrast microscopy.

20 G. p. gambiensis (numbered from 1 to 20) were given a feed infected with $T$. $b$. gambiense and subsequently checked for the presence of $T$. b. gambiense while 65 G.p. gambiensis (numbered from 21 to 85 ) and 67 G.m. morsitans (numbered from 86 to 152) were given a feed infected with $T$. congolense and subequently checked for the presence of $T$. congolense by microscopy.

\section{PCR}

Each parasitologically positive fly organ was recovered from slide in $30 \mu \mathrm{l}$ of sterile water and incubated one hour at $56^{\circ} \mathrm{C}$ and 30 minutes at $95^{\circ} \mathrm{C}$ in $30 \mu$ of a $5 \%$ chelex 100 resin (Biorad, CA, USA). After centrifugation, $10 \mu \mathrm{l}$ of the supernatant (referred as standard conditions), were used for subsequent DNA amplification. PCR was carried out using a DNA thermalcycler (MJ Research, Cambridge, UK) with final volumes of $50 \mu \mathrm{l}$ containing 10 pmoles of each primer (TCS1 and TCS2 for T. congolense, or TBR1 and TBR2 for T. b. gambiense, described by Masiga et al., 1992), $0.2 \mathrm{mM}$ of each deoxyribonucleotide, $1 \mathrm{X}$ incubation buffer with $1.5 \mathrm{mM}$
$\mathrm{MgCl} 2$ and 0.5 units of Taq polymerase (QBIOgene, Ilkirch, France). Samples were initially denatured at $94^{\circ} \mathrm{C}$ for three minutes and then processed through 45 cycles, each consisting of a denaturation step at $94^{\circ} \mathrm{C}$ for $30 \mathrm{~s}$, an annealing step at $55^{\circ} \mathrm{C}$ (TCS1/TCS2) or $56^{\circ} \mathrm{C}$ (TBR1/TBR2) for $30 \mathrm{~s}$ and an extension step at $72^{\circ} \mathrm{C}$ for one minute. The final elongation step was lengthened to five minutes. Amplification products were checked by electrophoresis in $2 \%$ agarose gels and visualised by ethidium bromide staining under UV light.

\section{RESULTS}

$\mathrm{M}$ icroscopic observation revealed T. b. gambiense in seven midguts and two salivary glands from G. p. gambiensis. T. congolense were observed in 17 midguts from G. p. gambiensis, 10 midguts from G. m. morsitans, one proboscis from G. p. gambiensis and eight probosces from G. m. morsitans.

When all these parasitologically positive organs were subjected to PCR with the appropriate sets of primers, five/seven midguts from G. p. gambiensis infected with T. b. gambiense and $12 / 27$ midguts from the two tsetse fly species infected with $T$. congolense, came out negative using standard PCR conditions (see Materials and Methods), whereas all the probosces and salivary glands were positive. It had been previously checked that organs from uninfected flies, used as negative controls, could not be amplified with the two pairs of primers used in the study.

By reducing the volume of chelex supernatant used, i.e. by diluting the sample, all the 17 "standard PCR conditions" negative midguts were successfully amplified (Fig. 1). The dilution necessary to obtain successful amplification differed from one midgut sample to the next: whereas amplification of the parasite DNA present in the midgut of tsetse fly $n^{\circ} 27$ succeeded with

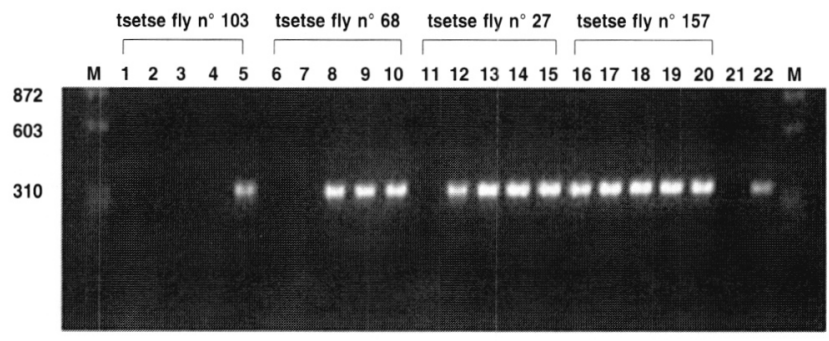

Fig. 1. - TCS1 and TCS2 PCR amplification of Trypanosoma congolense present into four different tsetse fly midguts using different volumes of chelex supernatant.

M: marker PhiX174/HaeIII; 21: PCR negative control; 22: PCR positive control

1, 6, 11 and 16: PCR using $10 \mu \mathrm{l}$ of chelex supernatant; 2, 7, 12 and 17: PCR using $5 \mu \mathrm{l}$ of chelex supernatant; 3, 8, 13 and 18: PCR using $2 \mu \mathrm{l}$ of chelex supernatant; 4, 9, 14 and 19: PCR using $1 \mu \mathrm{l}$ of chelex supernatant; 5, 10, 15 and 20: PCR using $0.5 \mu \mathrm{l}$ of chelex supernatant. 
a volume of $5 \mu \mathrm{l}(1 / 2$ dilution), it needed a further reduction to $0.5 \mu \mathrm{l}$ (1/20 dilution) in the case of tsetse fly $n^{\circ} 103$. No amplification could be obtained by raising the volume of chelex supernatant above $10 \mu \mathrm{l}$. The "standard PCR conditions" positive midguts could also be amplified using a reduced volume of chelex supernatant (see tsetse fly $n^{\circ} 157$, Fig. 1).

\section{DISCUSSION}

T This study was designed to check whether PCR effectively fails to identify parasitologically positive tsetse flies in the field, as it has been previously hypothesized (Solano et al., 1995; Morlais et al., 1998b). PCR were carried out on tsetse organs that contained human (T. b. gambiense) or animal (T. congolense) trypanosomes, for which specific primers were available.

We observed that the amplification reaction only failed with the midgut samples. Such failure of PCR in identifying parasitologically positive midguts had already been reported (Masiga et al., 1992; Masiga et al., 1996; Woolhouse et al., 1996; Reifenberg et al., 1997; Lefrançois et al., 1999). PCR lack of sensitivity cannot be incriminated since raising the quantity of parasite DNA used proved unsuccessful. On the other hand, since diluting the samples restored PCR performance, the likely cause of the failure lies in an inhibition of the parasite DNA amplification due to the cellular environment of the midgut. Although the optimal dilution varied, all the parasitologically positive midguts were successfully amplified using $0.5 \mu \mathrm{l}$ of supernatant $(1 / 20$ dilution).

This has important implications in the field, where PCR is used to characterize trypanosome infections in wild tsetse flies (McNamara et al., 1995; Lefrançois et al., 1999). Even if species-specific primers did not cover all Trypanosoma possibly present in wild tsetse flies, our results suggest that PCR failure in the field may simply relate to an inhibition of the amplification process, leading to errors of estimation regarding trypanosomes of medical or veterinary importance.

In conclusion, great care must be taken when using PCR to detect and identify trypanosomes in the midguts of tsetse flies in the field. Several sample dilutions must be tested to avoid PCR failure, whether caused by inhibition or by the very small number of parasites sometimes present in tsetse midguts.

\section{ACKNOWLEDGEMENTS}

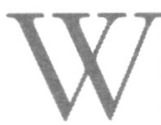

e thank particularly B. Tchicaya and J. Janelle for the maintenance and the management of the tsetse colonies.

\section{REFERENCES}

Dukes P., Kaukas A., Hudson K.M., Asonganyt T. \& Gashumba J.K. A new method for isolating Trypanosoma brucei gambiense from sleeping sickness patients. Transactions of the Royal Society of Tropical Medicine and Hygiene, 1989, 83, 636-639.

Lefrançois T., Solano P., Bauer B., Kabore I., Touré S.M., Cuny G. \& Duvallet G. Polymerase chain reaction characterization of trypanosomes in Glossina morsitans submorsitans and G. tachinoides collected on the game ranch of Nazinga, Burkina Faso. Acta Tropica, 1999, 72, 65-77.

McNamara J.J., Mohammed G. \& Gibson W.C. Trypanosoma (Nannomonas) godfreyi sp. nov. from tsetse flies in The Gambia: biological and biochemical characterization. Parasitology, 1994, 109, 497-509.

McNamara J.J., LaVEissiere C. \& Masiga D. Multiple trypanosome infections in wild tsetse in Côte d'Ivoire detected by PCR analysis and DNA probes. Acta Tropica, 1995, 59, 85-92.

Masiga D.K., Smyth A.J., Hayes P., Bromidge T.J. \& Gibson W. Sensitive detection of trypanosomes in tsetse flies by DNA amplification. International Journal of Parasitology, 1992, 22, 909-918.

Masiga D.K., McNamara J.J., Laveissiere C., Truc P. \& GibSON W. A high prevalence of mixed trypanosome infections in tsetse flies in Sinfra, Côte d'Ivoire, detected by DNA amplification. Parasitology, 1996, 112, 75-80.

Morlais I., Grebaut P., Bodo J.M., Djoha S. \& Cuny G. Characterization of trypanosome infections by polymerase chain reaction (PCR) amplification in wild tsetse flies in Cameroon. Parasitology, 1998a, 116, 547-554.

Morlais I., Grebaut P., Bodo J.M., Djoha S., Cuny G. \& HERDER S. Detection and identification of trypanosomes by polymerase chain reaction in wild tsetse flies in Cameroon. Acta Tropica, 1998b, 70, 109-117.

Reifenberg J.M., Cuisance D., Frezil J.L., Cuny G. \& Duvallet G Comparison of the susceptibility of different Glossina species to simple and mixed infections with Trypanosoma (Nannomonas) congolense savannah and riverine forest types. Medical and Veterinary Entomology, 1997, 11, 246-252.

Solano P., Argiro L., Yao Y., Reifenberg J.M. \& Duvallet G. Field application of the polymerase chain reaction to the detection and the characterization of trypanosomes in Glossina longipalpis (Diptera: Glossinidae) in Côte d'Ivoire. Molecular Ecology, 1995, 4, 781-785.

Solano P., Reifenberg JM., Amsler-Delafosse S., Kabore I., CuISAnCE D. \& Duvallet G. Trypanosome characterization by polymerase chain reaction in Glossina palpalis gambiensis and $G$. tachinoides from Burkina Faso. Medical and Veterinary Entomology, 1996, 10, 354-358.

Uilenberg G., Maillot \& Giret M. Études immunologiques sur les trypanosomes. II. Observations nouvelles sur le type antigénique de base d'une souche de Trypanosoma congolense. Revue d'Élevage et de Médecine Vétérinaire des Pays Tropicaux, 1973, 26, 27-35.

Woolhouse M.E.J., Mc Namara J.J., Hargrove J.W. \& Bealby K. Distribution of abundance of trypanosome (subgenus Nannomonas) infections of tsetse fly Glossina pallidipes in Southern Africa. Molecular Ecology, 1996, 5, 11-18.

Reçu le 16 novembre 2002 Accepté le 24 septembre 2003 